\title{
Experiences in applying Bayesian integrative models in interdisciplinary modeling: the computational and human challenges
}

\author{
$\underline{\text { S. Kuikka }}{ }^{\text {a }}$, P. Haapasaari ${ }^{\text {a }}$, I. Helle ${ }^{\text {a }}$, S. Kulmala ${ }^{\text {b,c,d }}$ and S. Mäntyniemi ${ }^{\text {a }}$ \\ ${ }^{a}$ Fisheries and Environmental Management group (FEM), Department of Environmental Sciences, \\ University of Helsinki, Finland \\ ${ }^{b}$ Marine Research Centre, Finnish Environment Institute (SYKE), \\ ${ }^{c}$ MTT Agrifood Research, Finland \\ ${ }^{d}$ Finnish Game and Fisheries Research Institute, Finland \\ Email: sakari.kuikka@,helsinki.fi
}

\begin{abstract}
We review the experience obtained in using integrative Bayesian models in interdisciplinary analysis focusing on sustainable use of marine resources and environmental management tasks. We have applied Bayesian models to both fisheries and environmental risk analysis problems. Bayesian belief networks are flexible tools that can take into account the different research traditions and the various types of information sources.
\end{abstract}

We present two types of cases. With the Baltic salmon stocks modeled with Bayesian techniques, the existing data sets are rich and the estimation of the parameters is possible by data. In the environmental risk analysis we have mainly focused on the oil spills, where the data sets are poor and also the published papers are scarce. Therefore, some of our applications are based mainly on the use of expert knowledge.

The salmon models were the first Bayesian models to be used in the scientific advisory process in ICES (International Council for the Exploration of the Sea). Long discussions were needed to make the results accepted by all actors, especially in cases, where overfishing had been so severe that there was no chance to estimate the carrying capacity of the rivers by observed data only.

In the case of oil spills, there is much less data than in the case of fisheries and the role of existing publications and the expert knowledge is more important. Moreover, legislation does not specifically define the aims of the spill management (whether to safeguard human capital, large populations or populations of rare and threatened species). We have chosen the state of the threatened species as the decision criteria, as they have a status in other parts of Finnish legislation.

One of the scientific quality criteria for using the Bayesian decision analysis for management is that the uncertainty estimates are scientifically justified. Especially in cases where society is assumed to be highly risk averse, the uncertainty estimates related to alternative management options may have a crucial role. However, the use of Bayesian parameter estimation techniques may be time consuming and research projects can be difficult to manage due to unpredictable technical problems related to parameter estimation.

Biology, sociology and environmental economics have their own scientific traditions. Bayesian models are becoming traditional tools in fisheries biology, where uncertainty estimates of management options are frequently required. In sociology, the traditions allow the subjective treatment of the information, which supports the use of prior information, an elementary part of Bayesian techniques, in the models. Many of the environmental risks have also economic components, which favors the use of quantitative risk analysis. However, the traditions and quality criteria of these scientific fields are in many respects different. This creates both technical and human challenges to the modeling tasks.

Keywords: Bayesian networks, fisheries management, environmental management, interdisciplinary risk analysis 
Kuikka et al., Experiences in applying Bayesian integrative models in interdisciplinary modelling: the computational and human challenges

\section{INTRODUCTION}

Bayesian networks (BNs, Jensen, 2001; Bromley et al., 2005; Uusitalo, 2007) have been widely applied to environmental risk and decision analysis. Our first experiences and lessons learned in using Bayesian networks are described in Varis and Kuikka (1999). That review included both pure expert knowledge modeling and the estimation of probabilities with various statistical methods, but it did not consider the Bayesian parameter estimation techniques, like Markov chain Monte Carlo (MCMC, Gilks et al., 1996) algorithms (applied e.g. in Michielsens et al., 2006; Mäntyniemi et al., 2009).

One of the key aims of our research group is to develop and apply appropriate probabilistic methodology to fisheries and environmental management problems. In the long run we aim to develop full Bayesian risk analysis and decision models for the Baltic Sea including biological, economic and sociological information.

The aim of this paper is to review some of our experiences and especially the human and financial resource needs related to the various approaches, and the role of traditions of some scientific fields in accepting Bayesian inference as an elementary part of the analysis.

\section{BAYESIAN NETWORKS AS A MODELLING TOOL IN INTERDISCPLINARY RISK ANALYSIS}

Understanding and managing complex environmental problems requires interdisciplinary and integrative approaches, and holistic thinking. Building integrative frameworks is, however, a challenge. Differences in disciplinary practices, paradigms, languages and world views make collaboration between disciplines difficult, and methodologies that allow the synthesizing of empirical data and knowledge from different fields are rare (Redman, 1999; Naiman, 1999; Garcia and Charles, 2008).

We find the Bayesian networks (Jensen, 2001, Bromley et al., 2005, Uusitalo, 2007) a flexible tool to model and integrate knowledge in interdisciplinary settings. The idea of the approach is to update prior knowledge, expressed as probability distributions, with new observations to get a posterior understanding on the problem. There exists no objective value for a probability, which implies that the probability distribution expresses a subjective degree of belief (Ramsey, 1926; Nau, 2011). The probability creates a common language between scientific disciplines and makes it possible to integrate knowledge from different fields of research, e.g. to link biological, sociological and economic knowledge.

\section{EXPERIENCES FROM PROJECTS AND CHALLENGES IN SOME EXAMPLE PROJECTS}

\subsection{PROMOS project: modeling the carrying capacity of Baltic Salmon stocks}

The current Baltic Sea salmon stock assessment is based on the extensive use of Bayesian stock assessment models (Michielsens et al., 2006; ICES, 2010). Earlier, the aim of management was to increase the production of each individual river to $50 \%$ of the maximum (Romakkaniemi et al., 2003). However, there was no common view what the maximum could be, as most of the stocks had been heavily overfished for some decades, and the observations for the stock-recruitment $(\mathrm{S} / \mathrm{R})$ relationship could not provide justified estimates for the carrying capacity of the rivers. The maximum production was estimated using expert knowledge and the estimates were reported as fixed and known values without any expression of uncertainty.

Therefore, an expert knowledge elicitation process was carried out (Uusitalo et al., 2005) by using a biologically meaningful model structure to describe the causal mechanisms behind $\mathrm{S} / \mathrm{R}$ relationship. The conflicting views of the experts were one of the key sources of uncertainty in the final posterior probabilities. However, the fact that the model estimates provided S/R functions (describing spawning stock - recruitment relationships) that were far out of the estimated historical stock sizes, was heavily criticized due to the tradition that only the stock assessment data can be used to estimate the $\mathrm{S} / \mathrm{R}$ functions. These function parameters were based on the expert judgments. These priors gained from experts provided estimates that were badly needed for the scientifically justified management, but this was also the most controversial element of the stock assessment at the time the Bayesian methods were first applied, leading to long discussions in advisory bodies.

Currently the posteriors of the paper Uusitalo et al. (2005) are used as priors in the Baltic salmon assessment models (ICES, 2010) and updated yearly with the new data. In this sense the system is learning: the information contents of the earlier publications have been used as a starting point for the new estimates thus accumulating the knowledge over time. 
Kuikka et al., Experiences in applying Bayesian integrative models in interdisciplinary modelling: the computational and human challenges

The lesson to learn from the Baltic salmon case is that it can be a very demanding scientific communication challenge to introduce Bayesian methods to such arenas, where frequentist approaches have traditionally been applied. The subjective elements of the science are more explicit in Bayesian models than in the classical statistics, which may encourage stakeholders to start discussions whether they agree with scientific assumptions made or not. It is common among the managers to prefer a single number rather than a probability distribution, which is considered to give too much freedom for stakeholders.

\subsection{OILECO project: modeling the oil spill impacts in the Gulf of Finland}

Juntunen et al. (2005) were the first to apply a BN to the oil spill risks of Gulf of Finland. Oil transportation from Russia through the gulf has increased very rapidly, and the future development of the traffic is highly uncertain. However, the impacts of a major oil spill on the environment are even more uncertain, as (luckily) the empirical data are to a large extent missing. In addition, the impacts are dependent on several factors such as weather conditions and the type of the spilled oil. Only very few studies have been carried out and they do not enable the assessment of the overall impacts of spills on the ecosystem of the gulf. Helle et al. (2011) further used BNs to model local oil spill risks in the Hanko peninsula in the western Gulf of Finland, and the process demonstrated that the detailed modeling can potentially be time demanding, especially if there are no previous models that can be used to describe the fate and behavior of spilled oil.

We have also applied non-Bayesian risk analysis to model the impacts on threatened species with a more simplified analysis structure. These populations have limited number of occurrences with fairly well-known locations, which makes it possible to carry out a more exact geographical risk analysis (Kokkonen et al., 2010, Ihaksi et al., 2011). Moreover, these species have already a role in the legislation, i.e. they must be safeguarded according to the law. Therefore the scientists do not have to make the decision, which parts of the ecosystem should be used as criteria to decide what to do (as elements of the utility function in the decision model). Especially the decisions, where to locate the oil booms after the spill, can be based on the known locations of the threatened species.

However, it is clear that the impact on threatened species is not the only environmental concern after a major oil spill, and therefore we developed an expert based assessment of the overall impact of oil spills on selected groups of species (Figure 1). As the number of species was high, it was unfeasible to apply detailed population dynamics modeling, and therefore expert judgment was used. It took more than two years from an expert, who had both the substance and methodological skills, to judge the required probabilities, which were based on the extensive literature survey, the general ecotoxicological knowledge and interviews with other experts.

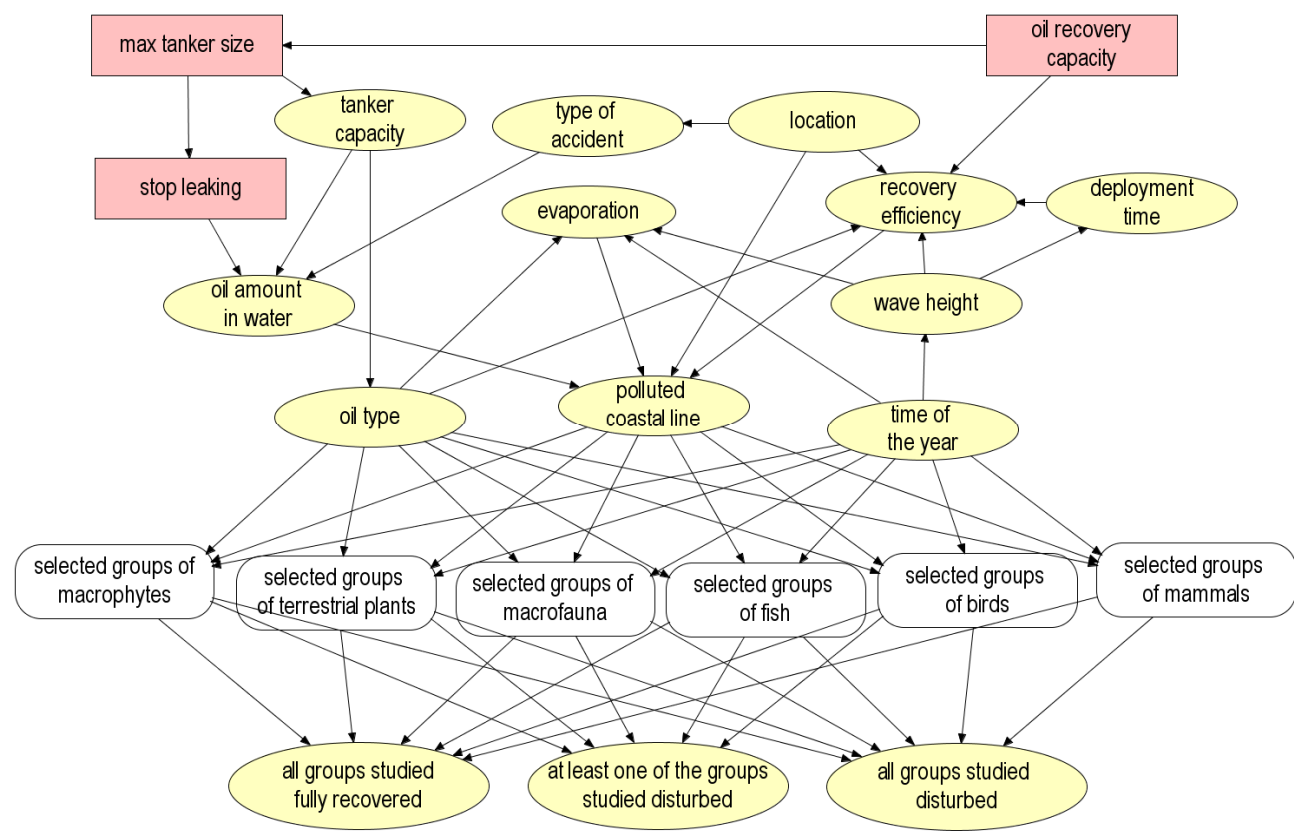

Figure 1. The oil spill impact model applied in Lecklin et al. (2011), first developed by Juntunen et al. (2005) and later on modified by Helle et al. (2011). 
Kuikka et al., Experiences in applying Bayesian integrative models in interdisciplinary modelling: the computational and human challenges

The key conclusion of the oil spill modeling was that the short term impacts on certain species groups may be severe, but the long term impacts are probably only minor (Lecklin et al., 2011). Even though highly subjective, such knowledge is badly needed and the use of expert judgments was a much cheaper option than trying to model all populations with species specific models. In addition, the posteriors obtained from this analysis can be used as priors in more complex simulation studies. This is actually done for the Gulf of Finland herring in the current ongoing IBAM project. Moreover, these kinds of expert models can be used to decide what kind of laboratory studies should be done in order to decrease the scientific uncertainties (valueof-information-analysis, VOI, see McDonald and Smith, 1996, Mäntyniemi et al., 2009).

\subsection{SAFGOF project: modeling the risks of oil transport in the Gulf of Finland}

Bayesian networks offer a flexible possibility to expand models in steps. The previous oil spill model (Figure 1) has been expanded in a recently finalized SAFGOF project. In SAFGOF, the BN includes several sub models describing the intensity of maritime traffic and collision probabilities of tankers and other vessels, the impact of oil spill combating and later on we aim to include biological damages (Klemola et al., 2009). The estimation of likely impacts of management options is in a key role here, as the model is supposed to be used in future planning of management actions (resource allocation between the preventive actions and the actions after a spill has taken place). It is relatively straightforward to link the earlier models to the new, more comprehensive model structures. The future challenge is to add grounding probabilities of the vessels to these models, and to add both the costs and benefits of the actions to enable probabilistic cost-benefit analysis.

\subsection{Salmon management: integration of biological, economic and sociological knowledge}

The paper by Levontin et al. (2011) is an example of how research of different disciplines and scientific traditions can be combined to allow managers to formally consider various stakeholder perspectives using a $\mathrm{BN}$. The meta-model, built for decision analysis purposes, is simple (Figure 2), but it is based on reasonably large biological data sets, a Bayesian stock assessment (Michielsens et al., 2006; ICES, 2010) with integrated economic analysis of the commercial fisheries (Kulmala et al., 2008) and a sociological study aimed at understanding fishers' commitment to alternative long term management plans (Haapasaari and Karjalainen, 2010). The analysis showed that the underlying environmental uncertainty played no role when ranking the management options. In contrast, the key uncertainty affecting the choice of optimal management strategy was fisher's reactions (implementation uncertainty) that depended on the policy decisions related to both objectives and individual managerial decisions with respect to action (Figure 2).

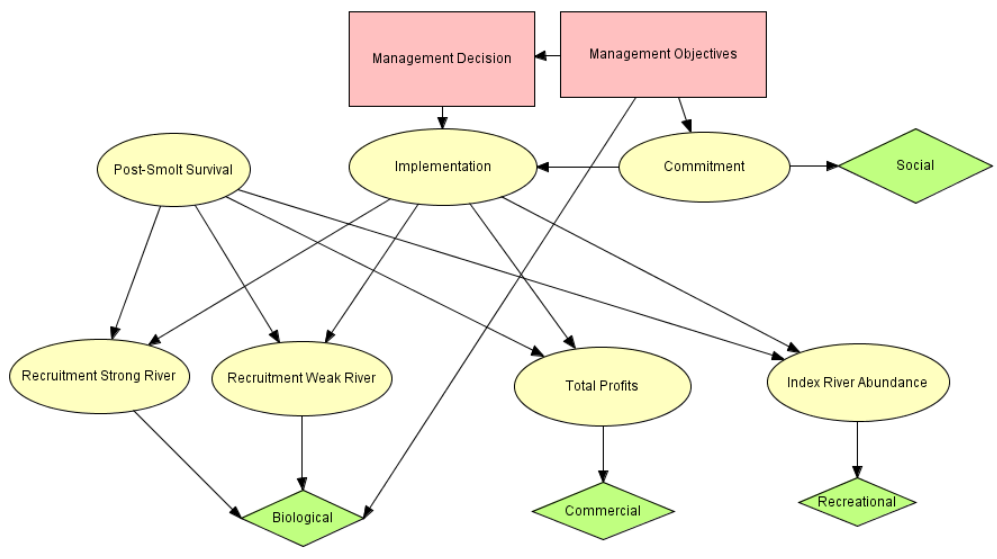

Figure 2. The salmon model structure applied in Levontin et al. (2011). The probabilistic dependencies describe only the key input - output combinations of complex simulation models. Reprinted by permission from publisher.

The study is a result of a learning process that took eight years and included several phases and sub-studies. The integrated model was both initiated and built after completing the disciplinary work and as a secondary task. Thus, the research carried out within the different disciplines was not guided by a global question or a methodological agreement. The next challenge for us is to plan a research project based on a commonly formulated overall question and a common methodology, agreed at the outset of the process. The idea is to translate a global question into the language of the different disciplines, and after that retranslate it to a common language that enables the integration of the knowledge (DeWachter, 1982; Klein, 1990; Haapasaari 
Kuikka et al., Experiences in applying Bayesian integrative models in interdisciplinary modelling: the computational and human challenges

et al., 2011a; Haapasaari et al., 2011b). This may require new attitude and aims from the funding organizations.

\subsection{IBAM project: modeling the combined impacts of several risk factors}

The aim of the currently running IBAM project is to link several risk factors and their management options in a BN model covering some example key species. The model will include management options for three different risk factors, which are at least partly controlled by human actions: oil spills, eutrophication and exploitation (hunting/fishing). Usually only one risk factor is considered at the same time, which easily leads to underestimation of population risks. In addition, these risks are currently managed by authorities, who do not necessarily co-operate, and thus are not trying to find a reasonable way to balance resources between alternative policy areas by applying scientific tools to such assessment. In the IBAM project, many different modeling techniques are combined to produce probability distributions for the final BN. These techniques include e.g. 3D ecosystem models, GP (Gaussian processes) models and population dynamics models.

\section{CONCLUSIONS AND FUTURE CHALLENGES}

\subsection{Scientific traditions and educational challenges}

Our suggested approach is to start the problem framing by sketching a graphical model including the most important variables, then assessing the causalities between the variables. At this point it is important to pay attention to the definition of the variables, solving any differences in terminology used in different disciplines and making sure that the variables match in terms of what they present in time and space. When using interactive BN software such as Hugin (Jensen, 2001), the first version of the model can be built using expert knowledge to fill in the discrete conditional probability distributions describing each causal link. The result is an interactive decision analysis tool, which can be seen as a coarse but complete model of the system and can be used to inform decisions that cannot wait for more detailed modeling. The value of information analysis could then be systematically used to identify the causal linkages for which the rank of decisions is most sensitive to. These linkage can then be taken under closer modeling effort, which may be require submodels with thousands of parameters to be estimated and may require more powerful estimation algorithms (MCMC, importance sampling). Finally the results of detailed modeling would then be simplified to a conditional distribution to be used in the decision analysis model by numerically integrating out all the parameters that are not of direct interest.

It is a time demanding task to educate scientists from several scientific disciplines (statistics, biology, economics, sociology, civil engineering) to carry out truly interdiscplinary risk analysis. However, their knowledge must be combined if we want to develop decision models that really take into account different interests, human behavior, impact of management actions and the alternative hypotheses of causal mechanisms both in the nature and in the society.

The view of what is "good science" seems to differ between disciplines. The natural sciences have traditionally counted on the classical frequentist statistics which stresses the ideal of objectivity in science. Thus, the most conventional frequentist school has not accepted the Bayesian approach that builds on subjective degree of belief. In the social sciences, on the other hand, the subjectivist Bayesian approach shares the idea of pre-understanding with the hermeneutic theory, and its idea of socially constructed character of reality matches with the constructionist epistemology (Gadamer, 1975; Berger and Luckmann, 1966). The scientific traditions of different disciplines must be respected, but at the same time there is a need to apply methodology that makes it possible to link information from different fields.

A university is not an optimal environment to establish an interdiscplinary research group. Obtaining skills in Bayesian statistics in addition to substance knowledge is very time consuming, and the project funding is too unstable to ensure the effective use of the obtained skills in future projects. However, this combination of skills is at least partly needed. Without a common language between a statistician and a substance expert the models may not describe what they are supposed to describe.

It is desirable that domain experts understand the Bayesian methodology to the extent that they can contribute to the selection of alternative model structures, the selection of likelihood functions, and the derivation of priors. Especially the selection of the likelihood function in statistical parameter estimation techniques can be in a key role as it impacts the final estimates of uncertainty. However, this decision by the experts must be based both on understanding how the data has been collected and on the behavior of the system (like behavior of tagged animals). This may be a demanding task. 
Kuikka et al., Experiences in applying Bayesian integrative models in interdisciplinary modelling: the computational and human challenges

\subsection{Time demands and project structures}

One major computational challenge with complex population models seems to be related to the slow convergence of the MCMC estimation runs in Bayesian population models. Although there are some fairly easy-to-use softwares available (e.g. OpenBugs or JAGS), much of the time of the biologically trained scientists may get spent to the technical problems related to MCMC algorithms, which is not optimal use of the scientific resources. Moreover, it is a usual approach that the integrative modeling is based on outcomes of earlier analysis, and is the last step of a big project, including a risk for failures in timing.

EU funded projects are currently based on detailed research agreements with tight time schedules. Thus e.g. unpredictable technical complications may create major problems for a project, as the time needed to complete one model may be very long. Due to these high modeling costs, the overall scientific costs may be very high to provide the information needed.

On the other hand, the Bayesian approach offers a way to create learning chains in science. The posteriors of one study can be used as priors in the next studies, if results are published in a justified way. Of the examples above, especially the oil impact analysis is an area where it would be necessary to apply Bayesian inference in the way that one learns systematically from one accident and is able to use this information in the future impact analysis. Moreover, the information obtained from ecotoxicological laboratory experiments should be linked to ecosystem impact models. If impact analyses are always based only on the observed data in each case study only, it is obvious that the overall impacts are underestimated.

For meta-analyses and for systematic learning processes, the scientific tradition of publishing only "statistically significant" results is a major problem. If only extreme data sets (when p values of hypothesis testing is estimated to be less than 0.05) are published and further used in meta-analyses or in scientific discussions, we may get a biased view of the system functioning. This may also create problems when using published papers as a source of prior information in Bayesian models (e.g. are published values representative samples of the system studied?).

Our view is that the allocation of resources used for data analysis or alternatively on analysis of priors should be an interactive process in scientific projects. If it is obvious that the available data will not be informative enough to make likely correct scientific and management conclusions, a major input should be directed to the effective and justified derivation of priors. In some cases this may even be a longer process than a "traditional" data analysis. However, the collection of new data can be very costly compared to the use of published papers or existing databases.

In our current project (ECOKNOWS) we aim to establish methodology by which the existing fish biology database (FishBase) can be modified to include a learning database, i.e. a provider of new information could contribute to the scientific learning and obtain, as a feedback, a posterior that is informative for the problem to be solved. We argue that such databases should be more common to enable effective scientific learning.

\section{ACKNOWLEDGMENTS}

This study has been partly supported by the Baltic Organizations Network for Funding Science EEIG (BONUS+) Project IBAM "Integrated Bayesian risk analysis of ecosystem management - Gulf of Finland as a case study"

\section{REFERENCES}

Berger, P.L., and Luckmann, T. (1966). The Social Construction of Reality. A Treatise in the Sociology of Knowledge. Anchor Books. New York.

Bromley, J., Jackson, N.A., Clymer, O.J., Giacomello, A.M., and Jensen, F.V. (2005). The use of Hugin to develop Bayesian networks as an aid to integrated water resource planning. Environmental Modelling \& Software, 20, 231-242.

DeWachter, M. (1982). Interdisciplinary bioethics: But where do we start? A reflection on epochè as method. Journal of Medicine and Philosophy, 7, 275-287.

Gadamer, H.G. (1975). Truth and Method. Continuum Publishing Group. London and New York.

Garcia, S.M., and Charles, A.T. (2008). Fishery systems and linkages: Implications for science and governance. Ocean and Coastal Management, 51, 505-527.

Gilks, W., Richardson, S., and Spiegelhalter, D. (1996). Markov Chain Monte Carlo in Practice. Chapman \& Hall. 
Kuikka et al., Experiences in applying Bayesian integrative models in interdisciplinary modelling: the computational and human challenges

Haapasaari, P., and Karjalainen, T.P. (2010). Formalizing expert knowledge to compare alternative management plans: sociological perspective to the future management of Baltic salmon stocks. Marine Policy, 34, 477-486.

Haapasaari, P., Kulmala, S., and Kuikka, S. (2011a). Converging biology, economics and social science in fisheries research - lessons learned. ICES ASC September 19-23 2011, Gdansk, Poland. ICES CM 2011/R:13.

Haapasaari, P., Kulmala, S., and Kuikka, S. (2011b). Growing into interdisciplinarity: how to converge biology, economics and social science in fisheries research? Submitted.

Helle, I., Lecklin, T., Jolma, A., and Kuikka, S. (2011). Modeling the effectiveness of oil combating from an ecological perspective - A Bayesian network for the Gulf of Finland; the Baltic Sea. Journal of Hazardous Materials, 185(1), 182-192.

ICES (2010). Report of the Working Group on Baltic Salmon and Trout (WGBAST), 24-31March 2010, St Petersburg, Russia. ICES Advisory Committee. ICES CM 2010/ACOM:08. [online] URL: http:/www.ices.dk/committe/acom/comwork/report/2010/2010/sal-2231.pdf

Ihaksi, T., Kokkonen, T., Helle, I., Jolma, A., Lecklin, T., and Kuikka, S. (2011). Combining conservation value, vulnerability, and effectiveness of mitigation actions in spatial conservation decisions: an application to coastal oil spill combating. Environmental Management, 47(5), 802-813.

Jensen, F.V. (2001). Bayesian Networks and Decision Graphs. Springer-Verlag, New York.

Juntunen, T., Rosqvist, T., Rytkönen, J., and Kuikka, S. (2005). How to model the oil combating technologies and their impacts on ecosystem: a Bayesian networks application in the Baltic Sea. ICES ASC September 20-24 2005, Aberdeen, Scotland, UK. ICES CM 2005/S:02.

Klein, J. T. (1990). Interdisciplinarity. History, Theory, and Practice. Detroit, Michigan.

Klemola, E., Kuronen, J., Kalli, J., Arola, T., Hänninen, M., Lehikoinen, A., Kuikka, S., Kujala, P., and Tapaninen, U. (2009). A cross-disciplinary approach to minimising the risks of maritime transport in the Gulf of Finland. World Review of Intermodal Transportation Research, 2(4), 343-363.

Kokkonen, T., Ihaksi, T., Jolma, A., and Kuikka, S. (2010). Dynamic mapping of nature values to support prioritization of coastal oil combating. Environmental Modelling \& Software, 25, 248-257.

Kulmala, S., Laukkanen, M., and Michielsens, C. (2008). Reconciling economic and biological modelling of migratory fish stocks: Optimal management of the Atlantic salmon fishery in the Baltic Sea. Ecological Economics, 64, 716-728.

Lecklin, T., Ryömä, R., and Kuikka, S. (2011). A Bayesian network for analyzing biological acute and longterm impacts of an oil spill in the Gulf of Finland. Marine Pollution Bulletin (accepted).

Levontin, P., Kulmala S., Haapasaari P., and Kuikka S. (2011). Integration of biological, economic and sociological knowledge by Bayesian belief networks: the interdisciplinary evaluation of potential Baltic salmon management plan. ICES Journal of Marine Science, 68, 632-638.

McDonald, A.D., and Smith, A.D.M. (1997). A tutorial on evaluating expected returns from research for fishery management. Natural Resource Modeling, 10, 185-216.

Michielsens, C.G.J., McAllister, M.K., Kuikka, S., Pakarinen, T., Karlsson, L., Romakkaniemi, A., Perä, I., and Mäntyniemi, S. (2006). A Bayesian state-space mark-recapture model to estimate exploitation rates in mixed-stock fisheries. Canadian Journal of Fisheries and Aquatic Sciences, 63(2), 321-334.

Mäntyniemi, S., Kuikka, S., Rahikainen, M., Kell, L.T., and Kaitala, V. (2009). The value of Information in fisheries management: North Sea herring as an example. ICES Journal of Marine Science, 66, 2278-2283.

Naiman, R. (1999). A perspective on Interdisciplinary Science. Ecosystems, 2, 292-293.

Nau, R.F. (2001). De Finetti was right: probability does not exist. Theory and Decision, 51, 89-124.

Ramsey, F.P. (1926). Truth and probability. In The Foundations of Mathematics and Other Logical Essays, pp. 156-198. Ed. by R. B. Braithwaite. Harcourt, Brace and Co., New York. 292 pp.

Redman, C. (1999). Human dimensions of ecosystem studies. Ecosystems, 2, 296-298.

Romakkaniemi, A., Perä, I., Karlsson, L., Jutila, E., Carlsson, U., and Pakarinen, T. (2003). Development of wild Atlantic salmon stocks in the rivers of the northern Baltic Sea in response to management measures. ICES Journal of Marine Science, 60, 329-42.

Uusitalo, L., Kuikka, S., and Romakkaniemi, A. (2005). Estimation of Atlantic salmon smolt carrying capacity of rivers using expert knowledge. ICES Journal of Marine Science, 62, 708-722.

Uusitalo, L. (2007). Advantages and challenges of Bayesian networks in environmental modelling. Ecological Modelling, 203(3-4), 312-318.

Varis, O., and Kuikka, S. (1999). Learning Bayesian Decision Analysis by Doing: Lessons from Environmental and Natural Resources Management. Ecological Modelling, 119, 177-195. 